\title{
THE RELATIONSHIP BETWEEN THE MANAGEMENT SYSTEM AND ORGANIZATIONAL CULTURE IN THE LATVIAN COLLEGE OF CULTURE - EFFICIENCY OF THE ORGANIZATIONAL CULTURE FROM ENTREPRENEURSHIP TYPE
}

\author{
Sandra Plota \\ Latvia, Riga, Latvian College of Culture at the Latvian Academy of Culture; \\ Bulgaria, Svishtov, PhD student at the D. A. Tsenov Academy of Economics
}

DOI: https://doi.org/10.31435/rsglobal_ijite/01062018/5653

\section{ARTICLE INFO}

Received 05 April 2018

Accepted 04 May 2018

Published 01 June 2018

\section{KEYWORDS}

Management, organization, culture, organizational culture

\begin{abstract}
The organizational culture as a social phenomenon and an attribute of the culture of society has been a subject of research for many years. The need for knowledge in the organizational culture increases with the dynamic increase in the expectations of citizens, society and the state.

Thanks to the work of a number of prominent scientists, a solid theoretical and methodological basis for conducting research in the field of measuring and evaluating the organizational culture of social organizations was created. This foundation provided the necessary impetus for conducting a research at the Latvian College of Culture.

This study shares the belief that organizational culture is a major factor in changes in social organizations that needs scientific understanding and research. Its essence is to build a new organizational culture to ensure the desired organizational behavior. A key issue of a number of research in recent years is how to build the desired profile of this culture. It is of particular importance that this is done in the context of the changes. That is why the organizational culture of all organizations in the culture sector is subject to special attention, and the disclosure of its profile is a topical and significant scientific issue that needs a solution.

The study suggests that, by diagnosing the organizational culture of the College of Culture with an appropriate method and toolbox, new knowledge will be gained on how the organizational behavior of Latvian culture college people can be changed in order to increase its efficiency. We are convinced that, without a major change in the organizational culture, there is little chance of permanent positive changes.

The survival paradigm of Latvia Culture College is creative and opened environment of the autonomous educational institution created by teachers and students.

Such environment is basic guarantee for professional educating of creative, full with initiative and opened to society, loyal culture specialists.
\end{abstract}

(C) 2018 The Author.

Introduction. At the beginning of the 20th century, the research of organizational culture in the sphere of culture was particularly relevant. The reason for this is the dynamic change of the environment in which radical changes took place.

A number of scientific papers present ideas, models, and solutions that show how to increase the efficiency of organizational culture management and the methods and tools that can be used to do so $[4,5,6,7]$. At the same time, the human factor's ability to achieve new levels of organizational efficiency has been poorly explored $[2,4,10,11]$. There is no comprehensive study of the organizational culture of state administration bodies in Latvia and, in particular, the Latvian College of Culture at the Latvian Academy of Culture (LCC).

According to Edgar Henry Schein, "leaders create and change culture, and administrators and managers act in it". Schein emphasizes that "the only important thing, leaders do, is to create and manage culture, because if they do not realize the cultures they are in, these cultures will manage them."

The management of the organization is the equivalent of managing its culture. Implementation of any strategy, procedure and change, etc. is ineffective if the cultural dimension of the organization is neglected - value orientations, ways of thinking, style of management, problem solving approaches. 
Changing organizational culture makes sense only if it affects motives, attitudes and behavior at individual and group level and changes in the context of vision, mission, and strategy for organizational development.

Modern state of the organizations methods of research. A leading idea in carrying out the diagnostic study is that of Edgar Henry Schein that the impact of organizational culture in organizations is determined by the relationship between leadership and culture that are conceptually related and represent two sides of the same coin.

A number of researchers have tried to systematize the basic qualities inherent in culture. Among them are G.H. Hofstede, F. Trompenaars, Talcott Parsons, D.A. Sonnenfeld, M.T. Hansen and C. Handy, T.E., Deal and A.A.Kennedy, Charles Hampden-Turner and many others.

The Dutch researcher Fons Trompenaars [12] draws a total of seven dimensions, grouped into three categories: those that arise from our relationships with others (1-5); those that result from the passage of time (6); and environmental problems (7).

Another Dutch researcher, Heert Hoffstede, has created a unique model of cultural dimensions that describes and explains national differences in organizational behavior. Researchers have been conducted in over 50 countries, using the fact that they belong to one organizational culture. The model represents a theoretical framework that analyzes the correlation between organizational actions and cultural attitudes. The final result is a typology of organizational culture in four aspects, characterizing the similarities and differences of organizational cultures:

- strive to avoid uncertainty;

- masculinity / femininity;

- individualism / collectivism;

- power distance between people of different social status.

On the basis of the criteria described, Hoffstede formulated eight cultural regions: German, Anglo-Saxon, North, Poorly developed Roman, Highly developed Roman, Poorly developed Asian, Highly developed Asian and Middle Eastern.

Hoffstede's methodology has been applied several times in Latvian terms. According to Hoffstede's criteria and the eight cultures described, Latvia falls into a northern cultural area.

Looking at the four-dimensional model of Heert Hoffstede, it is clear that four pairs of alternative cultures are possible. Under different national conditions, they can define similar in activities organizations.

The results of the studies conducted (in the four aspects above) show that Latvia is: in the middle open to uncertainty; with pronounced femininity (striving for a welfare state); in the group of individualistic countries; a country with moderately small power distances.

The typology of organizational culture shows considerable diversity. Notwithstanding the divergent criteria, it brings clarity and relevance to diagnosis in each system under study.

Parameters of the study - scope, volume, levels, limitations. All employees of the Latvian College of Culture at the Latvian Academy of Culture, working under the direct direction of the Director and two Deputy Directors, participate in the study.

The sample is not balanced, however, the persons in each department are enough to allow for the application of a variety of statistical methods in the analysis of the data and the demonstration of the applicability of the method of research of the environment of the Latvian national culture.

The study was conducted on a field in the period November - December 2017. In each department, the surveyed persons, after receiving the necessary instructions from a specially trained person, filled in the survey materials.

After the survey of all persons in the designated departments, the survey materials were subjected to a logical view and control, after which the data were introduced and subsequently processed with a specially developed data analysis system.

In accordance with the theoretical model and the hypothesis of the study, the variables are grouped as follows:

1. Independent variables: traits of personality.

2. Dependent variables: organizational culture.

3. Mediator variables: management style imposed by the LCC management and staff perceptions of the organizational environment.

Each of the methods of measuring and evaluating organizational culture has its advantages and disadvantages. The most significant drawback is the ultimate determination of the patterns to which each study attaches. The obtained empirical data is unambiguously interpreted in the conceptual 
frameworks set by them. This limitation is avoided by using a system of criteria for organizational culture assessment.

Latvian College of Culture at LAC

Structure

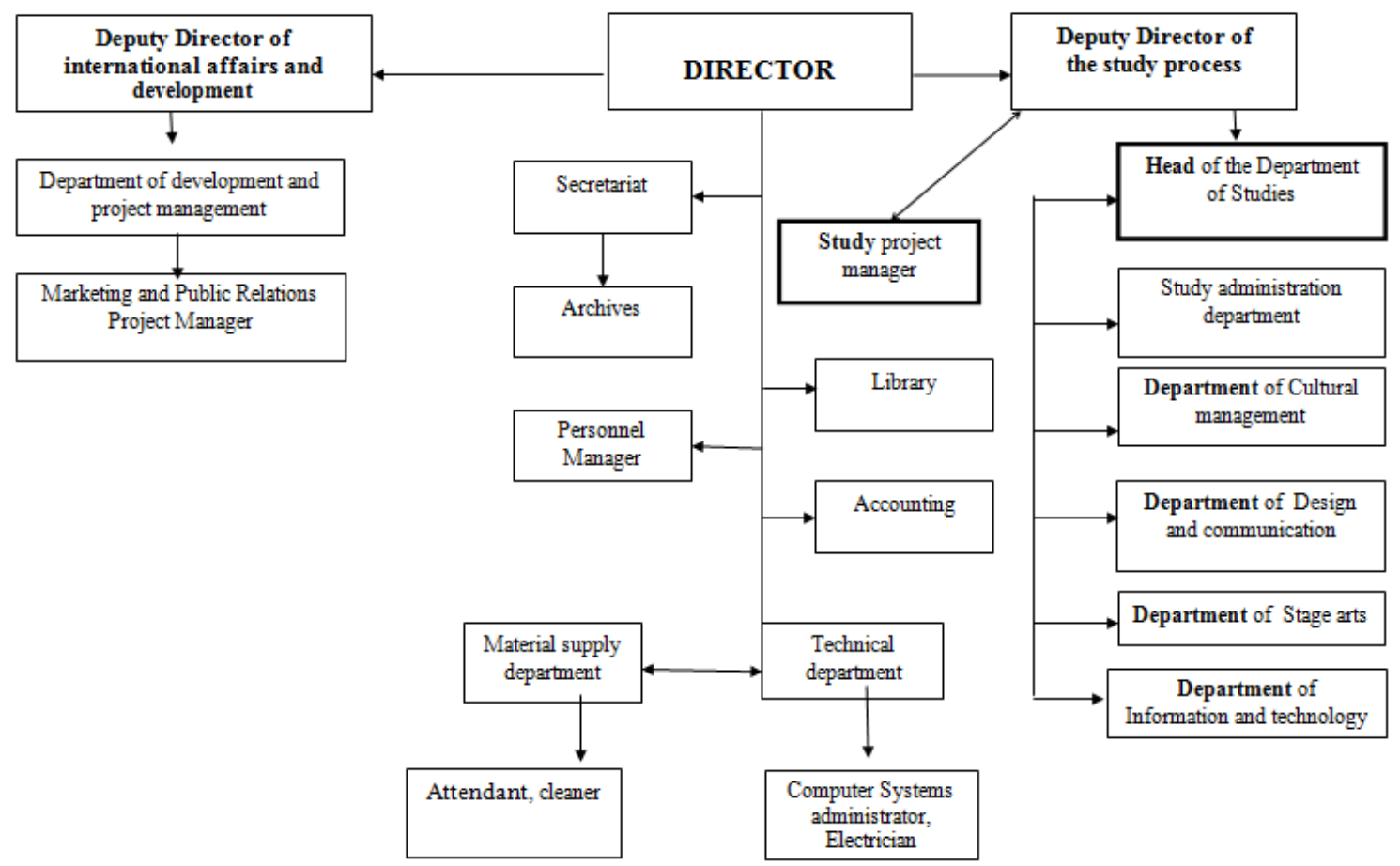

Fig. 1. Latvian College of Culture at LAC-structure

The empirical part of the diagnostic study contains several single but interrelated diagnoses. Considerable attention is paid to the projection of organizational culture in the mass consciousness and behavior of the studied group of directors, deputy directors, lecturers and other pedagogical specialists. For this purpose a standardized questionnaire is used which provides thorough information and facts about the values and attitudes of the interviewed respondents, related to the influence of organizational culture on the staff of the Latvian College of Culture at the Latvian Academy of Culture.

According to modern researchers [8], a way to evaluate organizational culture can be proposed with the help of 39 allegations. They are rated on a four-tier scale - 0 (Not at all), 1 (A little), 2 (Pretty much), and 3 (Very much), answering the question: "In your opinion "the way things are happening" in your organization leads to ... " [adapted to 1, 2003, pp. 31-38 and 3, 1994, pp. 99-110].

The maximum number of points you can get is 117. As a result: from 0 to 29 - the culture of the organization is not good; 30 - 59 - culture is somewhat good; 60 - 89 - pretty good; over 90 points - totally good.

It is assumed that the closer the result is to 117 , the stronger the culture in the organization is and this contributes to sustainability in the extremely dynamic and uncertain environment.

State of the Organizational Environment. The application of the systematic approach in the present study made it possible to place and execute the first research task, namely to establish how the surveyed persons, managers and contractors perceive aspects of the social environment in which they are professionally realized (see Figure 2).

The above figure shows that in the professional environment in which LCC employees function, certain conditions for natural movement in the hierarchy based on objective criteria have been created. Moreover, the contradictions in the requirements for their professional activities are kept to a minimum, accessibility to work at the Latvian College of Culture based on transparent criteria is ensured, and employees are strictly enforced in the requirements of bearable proportions. However, at the same time there is a normative base in volume, probably dictated by the nature of the activity to be observed in the performance of the functional obligations, higher requirements that are perceived by the employees as loads. A positive moment stemming from the analysis of the data is that the Latvian College of Culture provides some prestige for workers, perhaps as state officials. 


\section{Perceptions of the studied persons for the organizational environment}

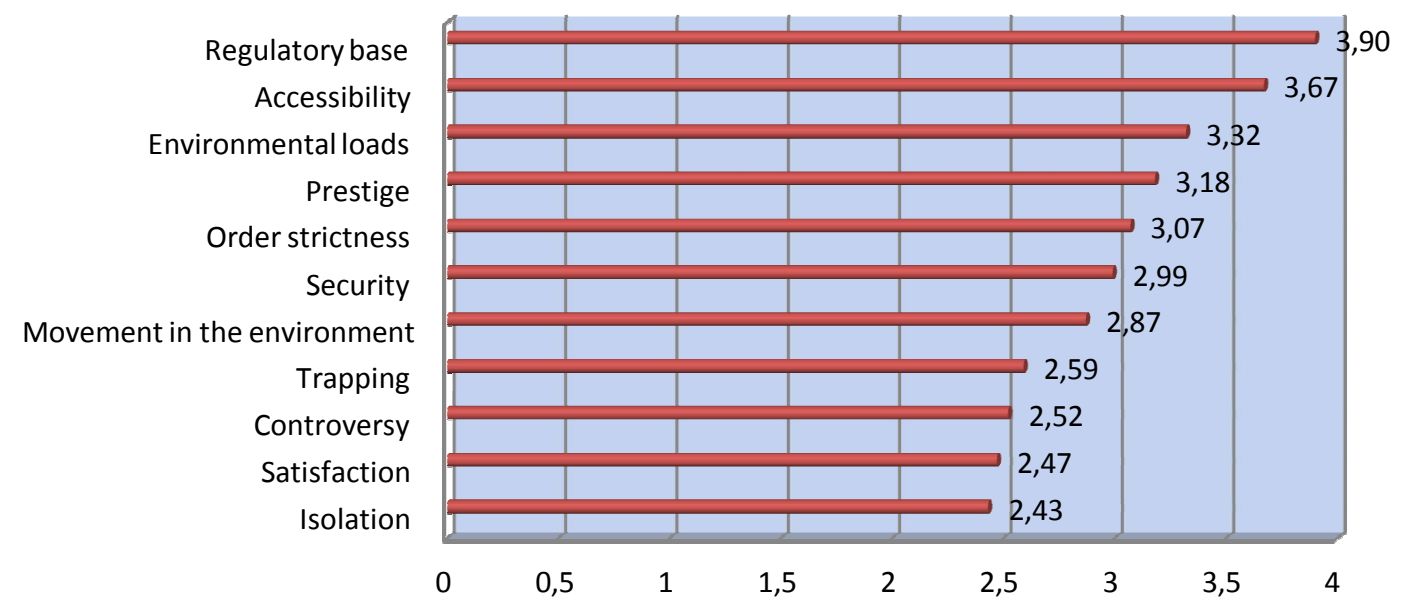

Fig. 2. Perceptions of the studied persons for the organizational environment in the LCC

Interesting for the study is the fact that there are some differences in the perception of the environment of the investigated in the departments, as well as the differences resulting from the status.

There are no differences in the perception of the environment in the Latvian College of Culture among the employees belonging to the general and specialized administration.

Differences arising from the position - manager, expert, executive - are only observed in perceptions of the existing regulatory framework. At the highest levels, perceptions of the existence of norms and rules of conduct in the environment that support its functions are those of experts $(\mathrm{M}=4.07$; $\mathrm{Sig}=.008)$.

So far, the analysis of the data obtained in the empirical study shows that although functioning in the same environment, employees have different perceptions of the environment, formed by different factors, some of which are more manageable and relatively persistent in their impact.

Showing managerial competence. The analysis of the results obtained by the descriptive statistics methods for the average values of the scales corresponding to each type of organizational culture and the average values of the twelve categories of managerial skills makes it possible to outline some tendencies of their manifestation in the studied environment.

The highest-rated individuals rated managers' skills as cultural practices applied in the clantype culture $(\mathrm{M}=3.85)$, followed by managerial skills that are specific to the ad- hoc $(\mathrm{M}=3.80)$ and the market $(\mathrm{M}=3.73)$ culture type. The lowest scores are the managers' competences corresponding to the hierarchical culture type $(\mathrm{M}=3,71)$.

\section{Managerial competence in the four types of organizational culture}

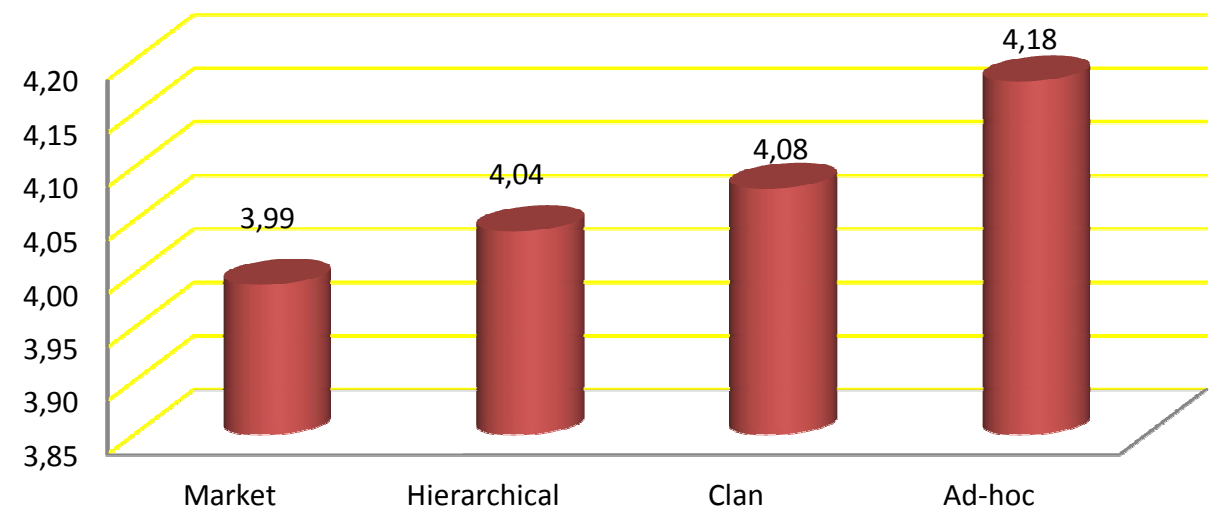

Fig. 3. Managerial competence in the four types of organizational culture in the LCC

Visually, the management styles are presented in the following figure (see Figure 3). The figure shows that the management style is balanced between the four types of organizational culture with a slight predominance of ad-hoc style. 
Conclusions. To believe that in an organization all members will share the same values, have the same attitude to work, share the same ideas, are unrealistic. In an organization, there have always been, there are and there will be members who share values that are different from, or contradictory to, the dominant ones.

Often, the leadership of the culture sector has to cope with the diversity of individual values that contradict the organizational ones. Attempts to establish homogeneity only confirm the mistakes of the past and create prerequisites for future failures. The most fundamental way to improve the situation is to accept diversity without sacrificing the requirements and standards for the quality of the sector's work.

In recent years, the management of the Latvian College of Culture has gone into evolutionary development through the constant improvement of organizational culture in the various functional units of the LCC.

The development of the Latvian College of Culture requires the reconstruction of its organizational culture so as to achieve the implementation of good practices.

The LCC's organizational culture's diagnosis allows us to get a detailed picture of the factors in place, and to discover the possibilities for its optimization.

This study is only one step on the way to creating a generic model of the organizational culture in the culture sector and to developing a unified methodology for conducting new research in this field.

\section{REFERENCES}

1. Bristow, N., \& S. J. Sandberg, The Corporate Culture Audit: A Five Step Approach, CSP Ltd, Cambridge, 2003.

2. Buzko, I., Dyachenko, Y., M Petrova, N Nenkov, D Tuleninova, K Koeva. Artificial Intelligence Technologies in Human Resource Development. Computer Modelling and New Technologies, TTI, Riga, Latvia, 2016, 20(2) 26-29.

3. Egan, G., Working the Shadow Side, Jossey-Bass Inc., San Francisco, 1994.

4. Labunska Sv., Petrova M., Prokopishyna O. Asset and cost management for innovation activity, "Economic Annals - XXI", VOLUME 165, ISSUE 5-6, 2017, Pages: 13-18. DOI: https://doi.org/10.21003/ea.V165-03 WOS:000418602400003, http://soskin.info/en/ea/2017/165-56/Economic-Annals-contents-V165-03

5. Linde, I., Mariana Petrova, The challenges of formalization and modeling of higher education institutions in the 21st century. Cbu International Conference Proceedings: Innovations In Science And Education Book Series: CBU International Conference Proceedings Pages, Prague, CZECH REPUBLIC Date: MAR 21-23, 2018. Sponsor(s): Central Bohemia Univ, Unicorn College.

6. Nenkov N., Tasinov T., Petrova, M. Software system for document management at the Faculty to University, 4th International Multidisciplinary Scientific Conference on Social Sciences and Arts, SGEM 2017. Conference Proceedings, Vol V Science and Society. Book 3, Education \& Educational Research, Pages: 457-464, DOI:10.5593/SGEMSOCIAL2017/35/S13.060

7. Petrova M. M., Analysis of integrated university information systems. The 15th International Conference Information Technologies And Management 2017, ISMA, Riga, Latvia, Information Technologies, Management and Society, 2017, p.55-57

8. Paunova M. How to characterize and evaluate the culture of the organization. - Economic Alternatives, UNWE, Sofia, ISSUE 6/ 2007, pp.111-121

9. Schein E.H. The corporate culture survival guide: sense and nonsense about culture change. San-Francisco, Jossey-Bass, 1999.

10. Sushchenko OA, Trunina IM, Zagirniak DM. Determination of electrical engineering business entity's core fields of competence as sources of its competitive advantages. DOI: 10.1109/MEES.2017.8248928. Modern Electrical and Energy Systems (MEES), Kremenchuk, Ukraine, pp.344-347, Publisher: IEEE, 2017

11. Sushchenko OA, Trunina IM (2016) Creation of innovation clusters as a line of enterprise competitiveness improvement in the field of foreign economic activity. Actual Probl Econ 177(3):191-198

12. Trompenaars F., Charles Hampden-Turner. Riding The Waves of Culture: Understanding Diversity in Global Business, 1997 